\title{
Posterior interosseous nerve palsy due to Bado type- III Monteggia fracture
}

\author{
Naoki Yoshida, Yoshihiko Tsuchida
}

Department of Orthopedic Trauma Surgery, Shonan Kamakura General Hospital, Kanagawa, Japan

\section{Correspondence to} Dr Naoki Yoshida, n_yoshida@shonankamakura. or.jp

Accepted 9 July 2018

\section{DESCRIPTION}

A 4-year-old girl presented to the emergency department with left elbow pain after a fall. On physical examination, her elbow was swollen, but there was no open wound. Arterial pulse was palpated, but a neurological diagnosis was impossible because of pain. A radiograph revealed a fracture of the proximal third of the ulna and a radial head dislocation, known as a Bado type-III Monteggia fracture (figure 1A,B). She was treated with open reduction and internal fixation to get an anatomical reduction. After the surgery, she could dorsiflex her left wrist but could not extend her fingers without hypoesthesia (figure 1C). We diagnosed her with posterior interosseous nerve (PIN) palsy due to the Bado type-III Monteggia fracture. The reduction position was anatomical; therefore, we decided to carefully follow up for palsy. Three months later, her palsy had completely recovered.

Monteggia fracture is defined as a fracture of the proximal third of the ulna, associated with a radial head dislocation. ${ }^{1}$ This fracture is rare and accounts for $0.4 \%$ of all forearm fractures in children. The Monteggia fracture may not be easily diagnosed because this fracture is frequently subtle, involving radial head dislocation with minor plastic deformation of the ulna. In the elbow, the anterior interosseous nerve (AIN) and PIN run around the interosseous membrane connecting the radius and the ulna, and they may be damaged by elbow injury. The AIN is a motor branch of the median nerve

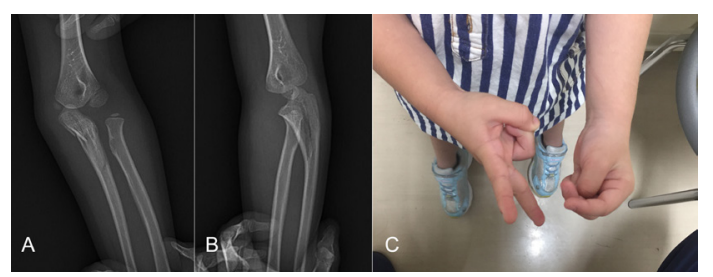

Figure 1 ( $A, B)$ A radiograph reveales a fracture of the proximal third of the ulna and a radial head dislocation. This is classified as Bado type-III Monteggia fracture. (C) The clinical photograph depicts the hand position with instructed extend her finger. Because she can dorsiflex her left wrist but can not extend her fingers without hypoesthesia, this indicates posterior interosseous nerve (PIN) palsy. trunk, and injury of the AIN prevents flexion of the distal phalanges of the thumb and index finger. ${ }^{2}$ The PIN is purely a motor branch of the radial nerve trunk, and injury of the PIN prevents extension of the thumb and fingers at their metacarpophalangeal joints, with preserved wrist extension. PIN palsy is the most common nerve injury associated with Monteggia fractures. This is because, following the dislocation of the radial head, the PIN can be easily injured by compression and excessive traction. It is important to achieve anatomical reduction of the ulnar fracture and radial head dislocation. Acute paediatric Monteggia fractures can be successfully managed non-surgically with closed reduction and cast immobilisation. If impossible, open reduction and fixation should be considered, followed by an intramedullary nail or plate and screw. ${ }^{3}$ When managed appropriately, nerve recovery and clinical outcomes for this paediatric population are extremely favourable.

\section{Learning points}

Posterior interosseous nerve palsy is the most common nerve injury associated with Monteggia fracture.

- It is important to achieve anatomical reduction of the ulnar fracture and radial head dislocation.

Contributors The patient's care was overseen by NY and YT. YT provided assistance with the drafting of the manuscript. Both authors approved the manuscript prior to submission.

Funding The authors have not declared a specific grant for this research from any funding agency in the public, commercial or not-for-profit sectors.

Competing interests None declared.

Patient consent Parental/guardian consent obtained.

Provenance and peer review Not commissioned; externally peer reviewed.

\section{REFERENCES}

1 Evans EM. Pronation injuries of the forearm, with special reference to the anterior Monteggia fracture. J Bone Joint Surg $\mathrm{Br}$ 1949;31B:578-88.

2 Komaru Y, Inokuchi R. Anterior interosseous nerve syndrome. QJM 2017;131:hcw227.

3 Demirel M, Sağlam Y, Tunalı O. Posterior interosseous nerve palsy associated with neglected pediatric Monteggia fracture-dislocation: A case report. Int J Surg Case Rep 2016;27:102-6. 
Copyright 2018 BMJ Publishing Group. All rights reserved. For permission to reuse any of this content visit http://group.bmj.com/group/rights-licensing/permissions.

BMJ Case Report Fellows may re-use this article for personal use and teaching without any further permission.

Become a Fellow of BMJ Case Reports today and you can:

- Submit as many cases as you like

- Enjoy fast sympathetic peer review and rapid publication of accepted articles

Access all the published articles

- Re-use any of the published material for personal use and teaching without further permission

For information on Institutional Fellowships contact consortiasales@bmjgroup.com

Visit casereports.bmj.com for more articles like this and to become a Fellow 